\title{
Is globalization a road to duopoly?
}

\author{
Pedro Cosme Costa Vieira
}

Faculdade de Economia do Porto, R. Dr. Roberto Frias s/n, 4200-464 Porto, Portugal

Received 19 April 2003; accepted 2 December 2003

\begin{abstract}
In global markets, the market shares of the two or three biggest firms sum up more than 90 percent and firms do marketing efforts. However, the classical neo-walrasiano theoretical framework only is able to justify these stylized facts with particular firms' cost structures, being one reason the presumption that there are no information costs. Towards the rationalization of those stylized facts, I study the evolution of the market structure in a model of price advertising with a variable that controls the degree of openness of regional markets. The main result of the model is that in equilibrium the structure of a global market is the duopoly.
\end{abstract}

(c) 2004 Elsevier B.V. All rights reserved.

JEL classification: D43; D83; F15

Keywords: Duopoly; Global market; Informative advertising; Search

\section{Introduction}

Under the classical neo-walrasian theoretical framework, the number of firms in the market is exogenous and may be any quantity and it is predicted that firms do no marketing efforts in the sale of the goods they trade.

However, I notice that firms do efforts in the sale of trade opportunities and that in global markets the market shares of the two or three biggest firms sum up more than 90 percent. Among others examples, in 2002 'Carbonated Soft Drink Market', The Coca-Cola Co. (44.3 percent), Pepsi-Cola Co. (31.4 percent) and Cadbury (15 percent) market shares ${ }^{1}$ sum up

E-mail address: pcosme@fep.up.pt (P.C. Costa Vieira).

${ }^{1} \mathrm{http} / / / \mathrm{www}$.beverage-digest.com/pdf/top-10_2003.pdf. 
90.7 percent. In another example, in 2003:2Q 'x86 Processor Market', Intel (82.5 percent) and AMD (15.7 percent) market shares ${ }^{2}$ sum up 98.2 percent.

I believe that these two stylized facts are connected and that the principal reason why the neo-walrasiano theoretical framework is unable to justify both these facts is that it presumes that there are no information costs. Under this assumption, buyers know all opportunities of trade in the market that are capable of ranking. In this way, it is useless to a firm to do any effort in informing and persuading buyers about their trade proposals.

Assuming as I do in this work, that there are information costs, buyers only know a fraction of the opportunities of trade, which implies that it is rewarding to a firm to advertise its trade proposals.

In this work, I use as firms' technology of informing and persuasion buyers the aleatory informative advertising model of Butters (1977), where sellers send informative ads to buyers in an aleatory and independent way. This technology of informing and convincing buyers has the advantage of being conceptually realistic and of having a well-behaved exponential cost function.

I consider in my work the trade of homogeneous goods, that producer firms differ in cost functions and that they advertise prices. But that may be extended to a model where firms sell trademarks with different prices and equal costs of production (Chamberlain's, 1933, monopolistic competition) and firms advertise the required information to persuade buyers to alter the ranking of the perceived value of the trademarks.

Globalization implies that there is competition between two firms wherever its location. To control de degree of globalization, I use an inter-region cost that aggregates transportation difficulties, tariffs and differences in culture or tastes, being zero if the market is global. I name this inter-region cost as the cost of transportation.

\section{Aleatory informative advertising technology with transportation costs}

\subsection{Premises of the theory}

The global market is divided in $N$ regional markets with several buyers and one firm in each.

Each buyer acquires one unit of goods if he receive at least one ad promoting a price not higher than the reservation price $M$.

The firm $S$ is located in region $S$ and its marginal cost is constant and equal to $C_{S}$. The marginal cost of firm $S$ is higher than the marginal cost of firm $S+1$. There are $Q_{S}$ buyers near that firm $S$.

If a firm intends to sell in a region that is not its region of location, it must pay the transportation cost $T$ apiece.

The firm located in region $S$ sent $g\left(R_{S}, R_{B}, P\right)$ ads to region $B$ advertising price $P$, being $P$ a continuous variable.

It costs $\xi$ for each ad sent to a buyer chosen in an aleatory and independent way.

\footnotetext{
2 http://www.infoworld.com/article/03/08/04/HNintelholds_1.html.
} 
Firms have common knowledge. Firms compete one against the other a la Cournot and are Stakelberg leaders to the buyers (see, e.g., Pepall et al., 2002).

\section{Formalization of the theory}

From the interaction of all firms strategies $g(S, B, P)$ it results both the average market price and the quantity traded in each region.

\subsection{Expected demand function being given firms behavior}

The total of ads in the region $B$ advertising a price equal or lower than $P$, the supply function of ads, is the sum of all ads sent by all firms to region $B$ :

$$
G(B, P)=\sum_{S=1}^{N}\left[\int_{x=0}^{P} g(S, B, x) \mathrm{d} x\right]=\sum_{S=1}^{N}\left[G_{S}(B, P)\right]
$$

As buyers are chosen in an aleatory way, the probability that a buyer of region $B$ does not receive any ad advertising a price equal or lower than $P$ is:

$$
S(B, P)=\left(1-\frac{1}{Q_{B}}\right)^{G(B, P)}
$$

The buyer acquires the good at a price equal or lower than $P$ if he receives at least one ad advertising such price that has probability $(1-S(B, P))$. Multiplying this probability by the total number of buyers in the region, it results the integral of the expected market demand function (Axell, 1977):

$$
W(B, P)=Q_{B}(1-S(B, P))=Q_{B}\left[1-\left(1-\frac{1}{Q_{B}}\right)^{G(B, P)}\right]
$$

Deriving this expression in order to price (if sellers advertises just one price, this function would be the expected market demand function), it results the following expected market demand function:

$$
\begin{aligned}
E[Q(B, P)] & =W^{\prime}(B, P)=w(B, P) \\
& =-Q_{B}\left(1-\frac{1}{Q_{B}}\right)^{G(B, P)} \ln \left(1-\frac{1}{Q_{B}}\right)\left(\sum_{S=1}^{N} g(S, B, P)\right)
\end{aligned}
$$

The expected demand function in the region $B$ of a seller located in region $S$ is computed dividing the expected market demand function by all sellers, proportionally to the quantities of ads advertising price $P$ that each seller sends to the region $B$ : 


$$
E[q(S, B, P)]=-Q_{B}\left(1-\frac{1}{Q_{B}}\right)^{G(B, P)} \ln \left(1-\frac{1}{Q_{B}}\right) g(S, B, P)
$$

\subsection{Behavior of firms being given the expected demand function}

With reference to each regional market, a firm maximizes its profit changing the quantity of ads it sends. Because firms are Stakelberg leaders in relation to buyers, they take into account how the expected demand function changes with their strategy $g$.

$$
\begin{aligned}
& g(S, B, P): E[\pi(S, B)]=\max \int_{P=0}^{M}\left\{E[q(S, B, P)]\left(P-C_{S}-X T\right)-\xi g(S, B, P)\right\} \mathrm{d} P, \\
& X=0 \text { if } B=S, \quad X=1 \text { otherwise }
\end{aligned}
$$

As stated by definition (1), in each regional market, the ads supply function is quantified summing up the quantities of ads send by each firm.

\section{Properties of the theory}

From the maximization problem that expression (6) represents, it results the optimal number of firms in the market.

Next, we present the properties of the theory assuming that a firm only sends one more ad if that increases its expected profit.

Assertion 1. Starting with $N$ firms, each one in a regional closed market, with the reduction of the transportation cost, market structure evolves to a duopoly because less efficient firms exit from the market.

So that the proof is clear, I consider three cases, two limit cases and the in-between case.

Case 1 (Closed markets). The transportation cost is so high that, for all firms, the cost of producing plus advertising and transporting goods is higher than the monopoly price, $C_{1}$ $+\xi+T \geq M$, but the cost of producing plus advertising is lower than that monopoly price, $C_{N}+\xi<M$.

In this trivial case, there are $N$ firms in the market because each firm is monopolist in its region where advertises the monopoly price, not advertising in other regions.

Case 2 (Perfectly opened markets). The transportation cost is zero and firms' cost of producing plus advertising is lower than $M$.

In this case only the firm 1 that has lower production cost advertises prices in the interval $\left[C_{2}+\xi ; \mathrm{M}\right]$ and firm 2 stays in the market as contestant.

In quantitative terms, if there are a large quantity of buyers in the market (more than 100 buyers), the firm 1's optimal strategy is: 


$$
G_{1}(B, P)=Q_{B} \begin{cases}0, & P<C_{2}+\xi \\ \ln \left(\frac{P-C_{2}}{\xi}\right), & C_{2}+\xi \leq P<M \\ \ln \left(\frac{M-C_{1}}{\xi}\right), & P \geq M\end{cases}
$$

Proof. Firm 1 does not advertise prices lower than $C_{2}+\xi$ because it does not have competition in the price interval $\left[0, C_{2}+\xi\right]$.

Being the number of buyers in the market more than 100, it is acceptable to simplify $\ln \left(1-1 / Q_{B}\right)=-1 / Q_{B}$. As the variable price is continuous, function $g(S, B, P)$ assumes only quantity 0 or 1 , except at monopoly price. Being so, it is possible to simplify the expression (5):

$$
E[q(S, B, P)]=\left\{\begin{array}{lll}
0 & \text { for } & g(S, B, P)=0 \\
\left(1-1 / Q_{B}\right)^{G(B, P)} & \text { for } & g(S, B, P)=1
\end{array}\right.
$$

A firm advertises price $P$ if its profit increases:

$$
\begin{aligned}
& \left(1-1 / Q_{B}\right)^{G(B, P)}\left(P-C_{S}\right)>\xi \\
& \Leftrightarrow \\
& G(B, P) \ln \left(1-1 / Q_{B}\right)+\operatorname{Ln}\left(P-C_{S}\right)>\operatorname{Ln}(\xi) \\
& \Leftrightarrow \\
& G(B, P)<\ln \left(\left(P-C_{S}\right) / \xi\right) Q_{B}
\end{aligned}
$$

Being by assumption $C_{1}<C_{2}$, then $\ln \left(\left(P-C_{1}\right) / \xi\right)<\ln \left(\left(P-C_{2}\right) / \xi\right)$. In this way, it is optimal that firm 1 , starting in price $C_{2}+\xi$, sets $G_{1}(B, P)=G(B, P)$ so that firm 2 does not advertise price $P$ (the argument extends to other firms):

$$
G(B, P)=\ln \left(\frac{\left(P-C_{2}\right)}{\xi}\right) Q_{B}
$$

The price $M$ is advertised in quantity higher than 1 until the marginal profit is zero:

$$
\left(1-\frac{1}{Q_{B}}\right)^{G(B, P)}\left(M-C_{1}\right)=\xi \Leftrightarrow G(B, M)=Q_{B} \ln \left(\frac{M-C_{1}}{\xi}\right)
$$

If there are less than 100 buyers, the above arguments apply with respect to duopoly but optimal strategy is not as algebraically simple as expression (7).

Case 3 (Case in-between closed and completely opened markets). The transportation costs are positive but not high enough to close markets to firms located in other regions.

In this case, the total number of firms declines in a ladder way as markets become more opened to trade. 
Proof. The proof of this case uses the same argument used in Case 2. With a positive transportation cost, it is possible that a firm with a cost higher than $C_{1}$ has the lower cost in their region because other firms have a transport cost. For example, if $T$ is sufficient to make $C_{2}<C_{1}+T$, firm 2 will advertise its good in its region and firm 3 will stay in that market as contestant, having thus three firms in the global market.

Assertion 2. If buyers have positive search cost and they search sequentially, then firms affix the monopoly price at their shops and a buyer only ask the price to one firm if he didn't get any ad. Being so, the prices advertised, in a large proportion, are discount prices.

This property results directly from the theorem of Diamond (1971, p. 164).

\section{Conclusion}

Under general conditions, the classical neo-walrassian theoretical framework is unable to justify why in global markets the market shares of the two or three biggest firms sum up more than 90 percent and firms do marketing efforts in the sale of goods.

My work is an attempt to respond to this pitfall by introducing information costs.

The principal result of my work is that in perfectly open global markets there are only two firms competing, a duopoly. This result is important because predicts accurately real market data, e.g., the 2003:2Q market shares of Intel and AMD firms sum up 98.2 percent of the 'x86 Processor Market'.

\section{References}

Axell, B., 1977. Search market equilibrium. Scand. J. Econ. 79, 20-40.

Butters, G.R., 1977. Equilibrium distributions of sales and advertising prices. Rev. Econ. Stud. 44, 465-491.

Chamberlain, E.H., 1933. The Theory of Monopolistic Competition. Harvard University Press, Cambridge, MA. Diamond, P., 1971. A model of price adjustment. J. Econ. Theory 3, 156-168.

Pepall, L., Richards, D.J., Norman, G., 2002, Industrial Organization-Contemporary Theory and Practice, second ed., South-Western, Mason. 